\section{Sinonasal diseases in Nigerian primary school children}

\author{
Waheed Atilade Adegbiji, ${ }^{1}$ \\ Abdul Akeem Adebayo Aluko \\ ${ }^{1}$ Department of Otorhinolaryngology, \\ Ekiti State University Teaching Hospital, \\ Ado-Ekiti; ${ }^{2}$ Department of \\ Otorhinolaryngology, Aminu Kano \\ Teaching Hospital/Bayero University \\ Kano, Nigeria
}

\begin{abstract}
This study aimed at determining the prevalence, pattern, sociodemographic features and effect on the quality of life of sinonasal diseases among the primary school children. This community-based descriptive cross-sectional study of school children with sinonasal diseases was carried out between October 2017 and March 2018 in Ibadan-Nigeria, using multistage sampling technique. Data was taken using a pretested, interviewers assisted questionnaire and statistically analyzed using SPSS IBM version 23.0. The prevalence of sinonasal diseases was $21.7 \%(n=964)$. Age range was $5-13$ years; the mean age was $8.5 \pm 2.7$. There were $52.6 \%$ males and male to female ratio was $1: 1$. Common sinonasal diseases were allergic rhinitis (37.8\%), chronic rhinosinusitis (19.6\%), nasal trauma $(15.3 \%)$, acute rhinosinusitis $(11.0 \%)$ and foreign body impaction (5.74\%). Bilateral sinonasal diseases occurred in $82.3 \%$. Right and left sinonasal diseases accounted for $10.0 \%$ and $7.7 \%$ respectively. Major presenting complaints were rhinorrhea $(73.2 \%)$, excessive sneezing $(36.4 \%)$, nasal blockage/stuffiness (32.5\%) and itching (29.7\%).Associated complications of sinonasal diseases were mainly orbital complications in $30.1 \%$, pharyngitis in $12.9 \%$, pneumonia in $8.6 \%$ and otitis media in $6.7 \%$. Commonly affected qualities of life were fatigue $(16.3 \%)$, sleep disturbance $(12.4 \%)$, changes in mood $(10.5 \%)$ and isolation $(8.6 \%)$. The prevalence of sinonasal diseases in primary school children was $21.7 \%$. At presentation the majority of the pupils had associated complications and affectation of the quality of life.
\end{abstract}

\section{Introduction}

The nose and paranasal sinuses are components of the air passage in the facial bone. The paranasal sinuses, four paired that developed as out-pouches of the nasal cavities into the facial bone which they bare their names (Ethmoidal, Maxillary, Frontal and Sphenoidal sinuses). The mucosa lining of the paranasal sinuses is continuous with that of the nasal cavities through their ostia. $^{1-3}$

Sinonasal diseases may be congenital or acquired. Acquired sinonasal diseases may be secondary to trauma, inflammatory, neoplastic or metabolic in origin. 4,5 Typical clinical presentations of sinonasal diseases include nasal discharge, facial pain, nasal obstruction, itching (nose, eyes, throat, ear), excessive sneezing, swelling, mass, smell abnormalities, headache, halitosis, and symptoms of the complications. ${ }^{6-9}$ Adequate evaluation of patients with sinonasal diseases is very crucial before treatment. ${ }^{10,11}$ The extent of the sinonasal diseases in the nose and sinuses with their surrounding organ can be determined by appropriate imaging which ranges from simple, cheap, and less diagnostic value plain radiographs to most expensive, and more diagnostic value such as Computerized Tomographic (CT) scan and Magnetic Resonance Imaging (MRI). ${ }^{12}$ Radiologic evaluation is therefore of great importance in surgical planning of the patients to determine the extent and type of surgery to be employed.

Sleep disordered breathing and day time somnolence that is associated with sinonasal diseases leads to school absenteeism, lack of concentration, poor memory and psychosocial problems which affect learning and school performance. ${ }^{13}$ There is a dearth of literature about the prevalence of sinonasal diseases and its socio-demographic determinants in Nigerian school children. This study aimed at determining the prevalence, pattern, socio-demographic features and effect on the quality of life of sinonasal diseases among the primary school children in Ibadan-Nigeria.

\section{Materials and Methods}

This was a community-based, descriptive, cross-sectional study of urban primary school children with sinonasal diseases. The children were between the age of 5 and 13 years. These were pupils in primary schools only. The school health program was organized in collaboration with school authority and parents' teacher association. The study was carried out between October 2017 and March 2018

The sample size was determined using
Correspondence: Abdul Akeem Adebayo Aluko, Department of Otorhinolaryngology, Aminu Kano Teaching Hospital/Bayero University Kano-Nigeria.

Tel.: +234.8033571040

E-mail: aaaluko.oto@buk.edu.ng

Key words: Sinonasal diseases, Primary school, Children, Developing country.

Acknowledgments: the authors are most grateful to all the students, parents, guardian and school authorities that participated in this study.

Contributions: the authors contributed equally.

Conflict of interest: the authors declare no potential conflict of interests.

Funding: none.

Received for publication: 22 April 2019.

Revision received: 7 June 2019.

Accepted for publication: 18 June 2019

This work is licensed under a Creative Commons Attribution NonCommercial 4.0 License (CC BY-NC 4.0).

(C) Copyright: the Author(s), 2019

Licensee PAGEPress, Italy

Pyramid Journal of Medicine 2019; 2:49

doi:10.4081/pjm.2019.49

Fisher's formula ${ }^{14}$

$$
n=\frac{Z^{2} p q}{d^{2}}
$$

and calculated sample size was 964. Multistage sampling was used to select participants for the study. Stage 1; Stratification of schools in Ibadan to Public and Private primary schools out of which one each was chosen by simple random sampling (ballot method). Stage 2; Study participants were selected from each school using systematic sampling technique, with the nominal roll used as the sample frame, the sample interval

$$
\mathrm{n}^{\text {th }} \text { selection }=\frac{\text { sample frame }}{\text { sample size }}
$$

was calculated to be 7 and a random start used as the first participant was selected between number 1 on the nominal roll and 
sampling interval by simple random sampling (using ballot method) with subsequent participants selected by repeatedly adding the sampling interval. Where the selected participant was absent or did not consent, he was skipped and the next participant was sampled. Ethical clearance was obtained from the Ethical Review Committee of the State Ministry of Health, the assent for children 7 years and above was obtained from school authority, parents and guardian and informed consent were taken. The study was carried out according to the Declaration of Helsinki. ${ }^{15}$ Inclusion criteria were pupil aged between 5 and 13 years. Exclusion criteria were children outside the age group and those that their parent or guidance did not assent. Data was taken using a pretested, interviewer assisted questionnaire. Data on socio-demographic features, otorhinolaryngological history on sinonasal diseases, past medical, surgical, drug, family and social history was taken. Examinations done include; anterior rhinoscopy (using Thudicum nasal speculum and battery powered headlight Model: VersaBrite 2250 by Pelican), ear examination (using Heine mini3000 otoscope), throat examination (using battery powered headlight Model: VersaBrite 2250 by Pelican and disposable wooden tongue depressor Model: Narrow $10 \mathrm{~cm} \mathrm{X} 2 \mathrm{~cm} \mathrm{X} \mathrm{2mm),} \mathrm{eye} \mathrm{examination}$ (using snellen's eye chart and Heine ophthalmoscope Beta 200) and postnasal examination (using Portable Pentax flexible nasopharyngoscpe FNL 10RBS). International Business Machines [IBM] Statistical Package for Social Sciences [SPSS] for Windows, Version 23.0 software [Armonk, NY: IBM Corp] was used for statistical analysis and results were summarized using table frequencies, percentages, and graphic representations. Cross-tabulations were produced while the test for statistical association was done using Chi-square method and statistical significance was set at $\mathrm{P}<0.05$, at $95 \%$ confidence interval (CI). The use of flexible nasopharyngoscope for rhinoscopy could lead to more detailed findings but it is expensive with only few ENT centers having it and it is time consuming. This could be a limitation of this study.

\section{Results}

The total number of participants enrolled in the study was 964 out of which 209 children had sinonasal diseases. The prevalence of sinonasal diseases was $21.7 \%$. Age range was $5-13$, the mean age was $8.5 \pm 2.7$. All the age groups were involved with the peak age value of 39
$(18.7 \%)$ at 5 years. Table 1 showed the age distribution of the studied pupils. The commonest class distribution of the pupils was primary 1 in $49(23.4 \%)$. Others were primary 6 , primary 2 and primary 4 in 41 $(19.6 \%), 37(17.7 \%)$ and $33(15.8 \%)$ respectively. Table 2 illustrated the class distribution among the pupils.

In this study, there were $110(52.6 \%)$ males and $99(47.4 \%)$ females. Male to female ratio was 1:1. Majority of the studied participants were Muslim religion (111; $53.1 \%)$ and remaining $98(46.9 \%)$ were Christians.

The parents educational level were primary and post-secondary education in 55 $(26.3 \%)$ and $53(25.4 \%)$ respectively. Fiftytwo $(24.9 \%)$ had nil formal education and

$49(23.4 \%)$ had secondary school education. Majority of the parents, $52(24.9 \%)$ were civil servant followed by $47(22.5 \%)$ as businessmen/women, artisan (20.6\%) and farming (18.7\%). The socio-demographic features of pupils were illustrated in Table 3. Common sinonasal diseases among the participants in this study were allergic rhinitis $(79 ; 37.8 \%)$, chronic rhinosinusitis $(41 ; 19.6 \%)$, nasal trauma $(32 ; 15.3 \%)$, acute rhinosinusitis $(23 ; 11.0 \%)$ and foreign body impaction $(12 ; 5.74 \%)$. Other sinonasal diseases were adenoid hypertrophy, nasal polyps and nasal septal hematoma not presenting as emergency in 9 (4.3\%), $3(1.4 \%)$ and $2(1.0 \%)$ respectively. Table 4 showed sinonasal diseases among pupils.

Table 1. Age distribution of the pupils (bar charts).

\begin{tabular}{lcc} 
Age (years) & Number & Percentage \\
5 & 39 & 18.7 \\
6 & 21 & 10.0 \\
\hline 7 & 26 & 12.4 \\
8 & 28 & 13.4 \\
\hline 9 & 17 & 8.1 \\
10 & 17 & 8.1 \\
\hline 11 & 18 & 8.6 \\
12 & 21 & 10.0 \\
\hline 13 & 22 & 10.5 \\
\hline
\end{tabular}

Table 2. Class distribution among the pupils.

\begin{tabular}{lcc} 
Classes (Primary) & Number & Percentage \\
1 & 49 & 23.4 \\
2 & 37 & 17.7 \\
\hline 3 & 25 & 12.0 \\
4 & 33 & 15.8 \\
\hline 5 & 24 & 11.5 \\
6 & 41 & 19.6 \\
\hline
\end{tabular}

Table 3. Socio-demographic features of the pupils.

\begin{tabular}{lcc} 
Socio-demographic features & Number & Percentage \\
Sex & & \\
Male & 110 & 52.6 \\
Female & 99 & 47.4 \\
Religion & & \\
Christian & 98 & 46.9 \\
Muslim & 111 & 53.1 \\
\hline Parent education level & & \\
Nil & 52 & 24.9 \\
Primary & 55 & 26.3 \\
Secondary & 49 & 23.4 \\
Post-secondary & 53 & 25.4 \\
Parents occupation & & \\
Applicant & 28 & 13.4 \\
Business & 47 & 22.5 \\
Artisan & 43 & 20.6 \\
Civil servant & 52 & 24.9 \\
Farming & 39 & 18.7
\end{tabular}


Bilateral sinonasal diseases occurred in $172(82.3 \%)$ was more common than unilateral sinonasal diseases $(37 ; 17.7 \%)$. Right sinonasal diseases accounted for $21(10.0 \%)$ while left sinonasal diseases accounted for $16(7.7 \%)$. Figure 1 demonstrated the lateralization of sinonasal diseases.

The major presenting complaints were; rhinorrhea $(153 ; 73.2 \%)$, bouts of sneezing (76; 36.4\%), nasal blockage/stuffy (68; $32.5 \%)$ and itching $(62 ; 29.7 \%)$. Less common presenting complaints were hawking, headache, mouth breathing and epistaxis in 38 (18.2\%), 36 (17.2\%), $33(15.8 \%)$ and 28 (13.4\%) respectively. This is illustrated in Table 5.

Clinical examination of the nose revealed major findings which were nasal discharge in $139(66.5 \%)$, bluish mucosa in $91(43.5 \%)$, reduced nasal patency in 59 $(28.2 \%)$ and enlarged turbinate in 51 (24.4\%). Other findings were edematous mucosa $(39 ; 18.7 \%)$ and postnasal discharge $(27 ; 12.9 \%)$. Table 6 illustrated the presenting signs of the patients.

Associated complications of sinonasal diseases among the pupils were mainly orbital complications in $63(30.1 \%)$, pharyngitis in $27(12.9 \%)$, pneumonia in 18

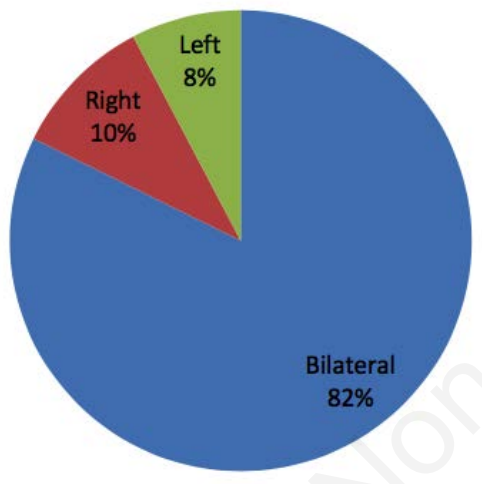

Figure 1. Lateralization of sinonasal diseases.

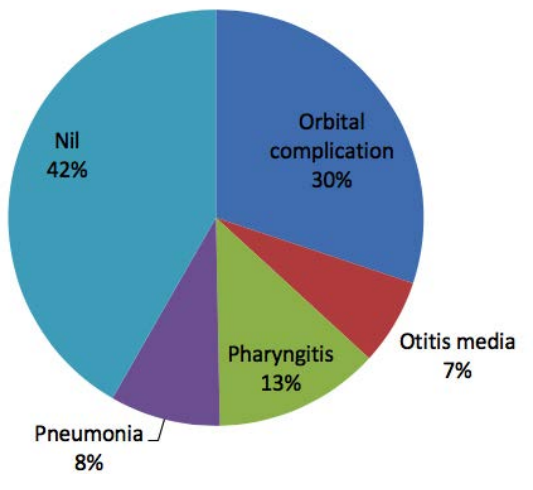

Figure 2. Complications of sinonasal diseases in the patients.
$(8.6 \%)$ and otitis media in $14(6.7 \%)$. This was illustrated in Figure 2. Sinonasal diseases commonly affect the quality of life, causing fatigue in $34(16.3 \%)$, sleep disturbance in $26(12.4 \%)$, changes in mood in 22
$(10.5 \%)$ and isolation in $18(8.6 \%)$. Other were anxiety, depression and psychological disorders in $17(8.1 \%), 16(7.7 \%)$ and 12 $(5.7 \%)$ respectively of the studied pupils. This was shown in Table 7.

Table 4. Sinonasal diseases among the pupils.

\begin{tabular}{lcc} 
Sinonasal diseases & Number & Percentage \\
Acute rhinosinusitis & 23 & 11.0 \\
Chronic rhinosinusitis & 41 & 19.6 \\
\hline Allergic rhinitis & 79 & 37.8 \\
Foreign body impaction & 12 & 5.7 \\
\hline Nasal trauma & 32 & 15.3 \\
Adenoid hypertrophy & 9 & 4.3 \\
\hline Nasal septal hematoma & 2 & 1.0 \\
Nasal Polyps & 3 & 1.4 \\
\hline Others & 8 & 3.8
\end{tabular}

Table 5. Sinonasal diseases symptoms at presentation.

\begin{tabular}{lcc} 
Symptoms & Number & Percentage \\
Rhinorrhea & 153 & 73.2 \\
Epistaxis & 28 & 13.4 \\
\hline Nasal blockage/stuffy & 68 & 32.5 \\
Bout of sneezing & 76 & 36.4 \\
\hline Itching & 62 & 29.7 \\
Halitosis & 27 & 12.9 \\
\hline Hawking & 38 & 18.2 \\
Headache & 36 & 17.2 \\
\hline Facial pain & 12 & 5.7 \\
Mouth breathing & 33 & 15.8 \\
\hline Snoring & 19 & 9.1 \\
Post nasal drip & 9 & 4.3 \\
\hline Loss of smell & 14 & 6.7
\end{tabular}

Table 6. Sinonasal diseases sign at presentation.

\begin{tabular}{lcc} 
Sigin & Number & Percentage \\
Edematous mucosa & 39 & 18.7 \\
Bluish mucosa & 91 & 43.5 \\
\hline Enlarged turbinate & 51 & 24.4 \\
Nasal discharge & 139 & 66.5 \\
\hline Bulbous septum & 3 & 1.4 \\
Reduced nasal patency & 59 & 28.2 \\
\hline Post nasal discharge & 27 & 12.9
\end{tabular}

Table 7. Quality of life among the sinonasal diseases pupils.

\begin{tabular}{lcc} 
Quality of life & Number & Percentage \\
Sleep disturbances & 26 & 12.4 \\
Psychological dislorders & 12 & 5.7 \\
\hline Isolation & 18 & 8.6 \\
Changes in mood & 22 & 10.5 \\
\hline Depression & 16 & 7.7 \\
Anxiety & 17 & 8.1 \\
\hline Fatigue & 34 & 16.3
\end{tabular}

[Pyramid Journal of Medicine 2019; 2:49]

[page 25] 


\section{Discussion}

Sinonasal disease may result in social and psychological problems for affected children and their families thus it is a major public health problem in developing countries. ${ }^{13}$ The prevalence of $21.7 \%$ found in this study was lower, in contrast to studies in similar populations by Eziyi et al. ${ }^{16}$ This may due to expected lower immunity of solely public-school children that was used in that study as they are mainly from low socio-economic status that is usually prone to disease. Also, this may be explained by the fact that it is at age 5 that the majority of these children enter school and there is sudden exposure to children from other homes. This study revealed male preponderance over the female preponderance in its findings which is similar to observed findings by another study. ${ }^{16,17}$ This may be because infective and traumatic disorders are common in male over female due to their hyperactivity. Female preponderance over male preponderance was reported in other studies. ${ }^{18,19}$ The parental education did not affect the pattern of sinonasal diseases in this study contrary to other reports that it was more common in children whose mothers are less well educated..$^{20}$ This was said to be probably due to their lower socioeconomic status, poorer access to good health, the poorer standard of living, and increased risk of recurrent ear infections. ${ }^{21}$

The major clinical presentation in this study was rhinorrhea, bouts of sneezing, nasal blockage/stuffy and itching over other presenting complaints. This finding was different from findings in other research work. $^{22}$ Edematous nasal mucosa, nasal discharge, bluish mucosa, reduced nasal patency, and enlarged turbinate were also the most common findings on nasal examination. Majority of the clinical features were consistent with the inflammatory reaction of sinonasal mucosa to the offending agent. Some sinonasal diseases may lead to different changes in the nose, sinuses and other parts of the head and neck region. This leads the manifesting symptoms, such as sneezing, rhinorrhea, itching, nasal blockage or stuffiness. Attempt to relieve this feeling by children leads to further trauma and introduction of infection as reported by previous studies. $^{23-25}$

Etiological agents of sinonasal disorders depend on various interacting epidemiologic factors in different geographic regions of the world. In this study, inflammatory factors and trauma (direct and indirect) were the leading cause of sinonasal diseases. Based on the etio-pathogenesis of sinonasal disorders in this study, common sinonasal diseases were allergic rhinitis, chronic rhinosinusitis, nasal trauma, acute rhinosinusitis, and nasal foreign body impaction. This finding is similar to reported findings in other studies. ${ }^{26-29}$

Extension of sinonasal diseases beyond the mucous membrane to the contiguous structure may have led to the observed common complications such as orbital, pharyngeal, pulmonary and otologic complications seen in this study. This was in agreement with another study. ${ }^{30}$ These complications may be secondary to hematogenous spread or direct extension. This study revealed affectation of quality of life such as fatigue, sleep disturbance, changes in mood and isolation. This is the resultant effect of the symptomatology of nasal blockage/stuffiness, nasal discharge and bout of sneezing. Some previous studies revealed similar findings. ${ }^{30-32}$

\section{Conclusions}

Prevalence of sinonasal diseases in Nigerian school children was $21.7 \%$ and the majority were due to preventable traumatic and inflammatory causes. At presentation, most of the pupils had associated complications that affected the quality of life. There is a need for sensitization of the community and policymaker towards early detection and treatment.

\section{References}

1. Ressel G. Sinus and Allergy Health Partnership releases the report on adult chronic rhinosinusitis. Am Fam Physician 2004;69:2248-9.

2. Kern RC, Conley DB, Walsh W, et al. Perspectives on the etiology of chronic rhinosinusitis: an immune barrier hypothesis. Am J Rhinol 2008;22:54959.

3. Adoga AA, Nuhu DM. The Epidemiology and Economic Impact of Rhinosinusitis in Jos, North-central Nigeria. J Clin Res Bioet 2011;2:11-6.

4. Deepthi NV, Menon UK, Madhumita K. Chronic rhinosinusitis: an overview. Amrita J Med 2012;8:1-44.

5. Dunmade AD, Afolabi OA, Alabi $\mathrm{BS}$, et al. Intra-antral application of an anti-fungal agent for recurrent maxillary fungal rhinosinusitis: a case report. J Med Case Rep 2012;6:245-8.

6. Awuah P, Duah IM. Orbital cellulitis treatment. J Nat Sci Res 2012;2:91-5.

7. Adeji TO, Olaosun AO, Tobih JE, Adejumo OO. Sinogenic orbital infections in a Nigerian Teaching Hospital. Adv Trop Med Publ Health Int
2013;3:87-100.

8. Chandramani P, Ashok S. Allergic Aspergillus Sinusitis and its association with allergic bronchopulmonary aspergillosis. Asian Pac Allergy 2011;1:130-7.

9. Ishitoya J, Sakuma Y, Tsukuda M. Eosinophilic Chronic Rhinosinusitis in Japan. Allergolint 2010;59:239-45.

10. Bhattacharyya N. Clinical and symptom criteria for the accurate diagnosis of chronic rhinosinusitis Laryngoscope 2006;116:1-22.

11. Meltzer EO, Hamilos DL. Rhinosinusitis diagnosis and management for the clinician: a synopsis of recent consensus guidelines. Mayo Clin Proc 2011;86:427-43.

12. Kolo ES. The role of plain radiographs in of chronic maxillary rhinosinusitis in adults. Afr Health Sci 2012;12:459-63.

13. Mir E, Panjabi C, Shah A. Impact of allergic rhinitis in school going children. Asia Pac Allergy 2012;2:93-100.

14. Charan J, Biswas T. How to calculate sample size for different study designs in medical research. Indian J Psychol Med 2013;35:121.

15. WMA. Declaration of Helsinki- Ethical Principles for Medical Research Involving Human Subjects; 2013. Available from https://www. wma. net/wp-content/uploads/2016/11/DoHOct2013-JAMA.pdf

16. Eziyi JAE, Amusa YB, Nwawolo C. The prevalence of nasal diseases in Nigerian school children. J Med Med Sci 2014;5:71-7.

17. Adegbiji WA, Olajide GT, Olajuyin AO, et al. Pattern of allergic rhinitis among children in Ekiti, Nigeria. Int J Pediatr Otorhinolaryngol 2018;106:75-9.

18. Kakish KS, Mahafza T, Batieha A, et al. Clinical sinusitis in children attending primary care centers. Pediatr Infect Dis J 2000;19:1071-4.

19. Pallin DJ, Chung YM, Mckay MP, et al. Epidemiology of epistaxis in US emergency departments, 1992-2001. Ann Emerg Med 2005;46:77-81.

20. Wikipedia. Hearing impairment. Available from: http://en.wikepedia.org/wiki/hearingimpairment.

21. Taha AA, Pratt RS, Farahat TM, et al. Prevalence and risk factors of hearing impairment among primary school children in Shebin El-Kom district, Egypt. Am J Audiol 2010;19:46-60.

22. Soler ZM, Mace J, Smith TL. Symptom-based presentation of chronic rhinosinusitis and symptom-specific outcomes after endoscopic sinus surgery. Am J Rhinol 2008;22:297-301. 
23. Adegbiji WA, Alabi BS, Omokanye $\mathrm{HK}$, et al. Clinico-mycological profile of otomycosis in two tertiary health institutions in Nigeria - a prospective study. Port Harcourt Med J 2012;6:25863.

24. Adegbiji WA, Alabi BS, Olajuyin OA, Nwawolo CC. Presentation of Preauricular Sinus and Preauricular Sinus Abscess in Southwest Nigeria. Int J Biomed Sci 2013;9:260-3.

25. Adegbiji WA, Alabi BS, Olajuyin OA, Nwawolo CC. Earwax impaction: Symptoms, predisposing factors, and perception among Nigerians. J Fam Med Primary Care 2014;3:379-82.

26. Gathiru C, Macharia I. The prevalence of allergic rhinitis in college students at Kenya Medical Training College-
Nairobi, Kenya. World All Organ J 2007;S84-S85.

27. Wallace DV, Dykewicz MS, Bernstein DI, et al. The Diagnosis and Management of Rhinitis: An Updated Practice Parameter. J All Clin Immunol 2008;122:S1-84.

28. Eziyi JAE, Akinpelu OV, Amusa YB, Eziyi AK. Epistaxis in Nigerians: A 3year Experience. East Cent Afr J Surg 2009;14:93-8.

29. Orji FT, Ezeanolue BC. Evaluation of adenoidal obstruction in children: clinical symptoms compared with a roentgenographic assessment. J Laryngol Otol 2008;122:1201-5.

30. Alt JA, DeConde AS, Mace JC, et al. Quality of Life in Patients With Chronic Rhinosinusitis and Sleep Dysfunction
Undergoing Endoscopic Sinus Surgery: A Pilot Investigation of Comorbid Obstructive Sleep Apnea. JAMA Otolaryngol Head Neck Surg 2015;141:873-81.

31. Marambaia PP, Garcia Lima M, Santos $\mathrm{KP}$, et al. Evaluation of the quality of life of patients with chronic rhinosinusitis by means of the SNOT-22 questionnaire. Braz J Otorhinolaryngol 2013;79:154-8.

32. Schatz M, Zeiger RS, Chen W, et al. A comparison of the psychometric properties of the Mini-Rhinitis Quality of Life Questionnaire and the Rhinitis Control Assessment Test. Am J Rhinol Allergy 2012;26:127-33. 